\title{
When you are talking to yourself, is anybody listening? The relationship between inner speech, self-awareness, wellbeing, and multiple aspects of self-regulation
}

\author{
Paul Verhaeghen \& Grazia Mirabito \\ Georgia Institute of Technology, Atlanta
}

\begin{abstract}
This correlational study of 433 adults (260 college students and 173 Mechanical-Turk workers) examined how the selfreported functions and experienced phenomenology of habitual inner speech (action guidance, problem solving/search, memory/attention regulation, emotion regulation, evaluate/motivate, other voices, inner dialogue, condensed speech) relate to self-awareness (self-reflection and controlled sense-of-self in the moment), potentially influence high-level aspects of self-regulation (self-preoccupation, self-compassion, wisdom, and the moral foundations of individualizing and binding), and psychological wellbeing. Hierarchical regression analysis revealed partial and mutual mediation between inner speech variables and self-awareness variables. Self-awareness was more consistently associated with self-regulation. The only inner speech variables associated with self-regulation in a beneficial way were memory/attention regulation (for wisdom about the self and the individualizing moral foundation) and evaluate/motivate (for the binding moral foundation). These findings suggest that, with the exception just described, inner speech (with the present dependent variables, and in adults) is easiest understood as an epiphenomenon.
\end{abstract}

Keywords: consciousness, self-awareness, inner speech, mindfulness

People often report the experience of inner speech, an inner voice (sometimes including the voices of others, or an inner dialogue) that accompanies their experiences in the world, that comments on these experiences, and often seems to serve a regulatory purpose (e.g., we may tell ourselves not to get angry or upset in a difficult situation, or we may tell ourselves to remember to bring milk back from the store, or we may use inner speech to consider the skillfulness of past actions). It is an important part of our lives: One experiencesampling study suggests that about one quarter of our waking life consists of inner speech (Heavey \& Hurlburt, 2008). In the present study, we investigate the link between habitual patterns of inner speech, the sense of self (or self-awareness) that is associated with those patterns, and if and how they indeed serve a self-regulatory purpose.

More formally, inner speech can be defined as "the subjective experience of language in the absence of overt and audible articulation" (Alderson-Day \& Fernyhough, 2015, p. 931); it has also been labeled as self-directed speech, silent talk, covert speech, silent verbal thinking, and so on (Morin, 2018). The dominant view on inner speech, probably first proposed by Vygotsky (1934/1987), posits that, developmentally, inner speech can be considered internalized external speech. Originally, at least part of a child's behavior is directed and regulated by direct, interpersonal communications from its caregivers. Over the course of development, inner speech increasingly becomes an internal

Correspondence concerning this article should be addressed to Paul Verhaeghen, Georgia Institute of Technology.

Email: paul.verhaeghen@psych.gatech.edu. means to support the child's own capacity for purposeful and independent action (Alderson-Day \& Fernyhough, 2015; Jones, 2009), and takes over some of the functionality of external speech. Jones (2009, p. 167) offers the examples of learning to do arithmetic in the classroom with pen and paper, later substituted with 'mental arithmetic', of shifting from learning to read out loud to silent reading, or of working one's way through a social problem internally as if one had a dialogue with a teacher or parent.

One of these purported functions is self-regulation. Studies on inner speech and self-regulation range in scope all the way from the relatively low-level process of executive control (Gade \& Paelecke, 2019; Kompa \& Mueller, 2020; Miyake, Emerson, Padilla, \& Bahn, 2004; Mueller, Jacques, Brocki, \& Zelazo, 2009) over rumination control (Whitmer \& Banich, 2007) and emotion control (Duncan \& Cheyne, 1999; Morin, 2018) to athletic performance (Turner $\&$ Barker, 2014) and social understanding (Fernyhough, 2008). Available experimental data (e.g., Miyake et al., 2004) suggest that the relationship is causal, with inner speech facilitating self-regulation rather than the other way around. The phenomenology of inner speech potentially plays a regulatory role as well. For instance, the dialogic nature of some inner speech has been linked to higher-order forms of self-regulation (Alderson-Day \& Fernyhough, 2015). It has also been proposed that the default mode of inner speech is condensed speech (i.e., speech stripped to its basic semantic and syntactic form), but that inner speech might expand when the individual is under stress and/or the task to be regulated is particularly challenging (Fernyhough, 2004). Note that inner-speech-supported self-regulation is 
not necessarily always beneficial. For instance, rumination is likely a form of inner speech meant to regulate behavior, yet it often results in a higher risk of dysphoria or depression (e.g., Trapnell \& Campbell, 1999).

A second often-cited function of inner speech lies in supporting self-awareness and self-reflection (for a review, see Morin, 2018): Verbal labeling of experiences related to the self allows the individual to build these experiences into a coherent self-concept. In this view, self-verbalization is a necessary (but not sufficient) requisite to capture conceptual self-information. A number of studies have indeed found moderately-sized correlations between different questionnaire measures of inner speech and different measures of self-awareness, self-reflection, or other self-related constructs (Brinthaupt, Hein, \& Kramer, 2009; McCarthy-Jones \& Ferneyhough, 2011; Morin, Everett, Turcotte, \& Tardif, 1993; Schneider, 2002; Schneider, Pospeschill, \& Ranger, 2005; Siegrist, 1995). Although the implicit bias of most (if not all) of these studies is that inner speech is a precursor of self-awareness, multiple directions are possible (Morin, 2018): Inner speech might lead to, increase, produce, or sustain self-awareness; self-awareness might induce or activate inner speech; or self-awareness and inner speech might parallel each other, that is, there might be rapid shifts between these two mental activities. Given the dominant bias in the literature, we will label the view that inner speech leads to or increases self-awareness 'the standard view', and the view that self-awareness leads to or may increase inner speech 'the reverse view'.

These two purported functions of inner speech-self-regulation and self-awareness-dovetail nicely with recent approaches to the concept of mindfulness. Mindfulness is traditionally defined as the ability or propensity to engage in "non-elaborative, non-judgmental, present-centered awareness in which each thought, feeling, or sensation that arises in the attentional field is acknowledged" (Bishop et al., 2004 , p. 232). Recent theoretical work has broadened the scope of this definition, however, converging on the conclusion that mindfulness is a complex concept, more akin to a manifold than to a singular construct. The starting point of this theoretical work has been an examination of the reasons why mindfulness interventions lead to such a wide array of positive outcomes. Although many models have been advanced to explain the translation of mindfulness into positive outcomes (e.g., Baer, 2003; Brown et al., 2007; Chiesa et al., 2013; Creswell \& Lindsay, 2014; Grabovac, Lau, \& Willett, 2011; Hölzel et al., 2011; Segal et al., 2013; Shapiro et al., 2006; and Vago \& Silbersweig, 2012), the list of proposed mechanisms generally contains three categories, as Vago and Silbersweig (2012) point out. A first proposed mechanism is a change in self-awareness: recognizing automatic habits and automatic patterns of reactivity, as well as an increased awareness of momentary states of body and mind (what is typically understood by mindfulness, as testified by the Bishop et al. definition). A second proposed mechanism is a change in self-regulation: better regulation of emotions, heightened self-compassion, increased emotional and cognitive flexibility, decreased rumination and worry, and increased non-attachment and acceptance. A final proposed mechanism of the effects of mindfulness is increased self-transcendence: increased decentering, a stronger awareness of interdependence between self and others, and heightened compassion.

Vago and Silbersweig (2012) label this common-denominator model the S-ART model, after its three components: self-awareness, self-regulation, and self-transcendence. Our own empirical work (Verhaeghen, 2019a, 2019b; Verhaeghen \& Aikman, 2020), based on exploratory and confirmatory factor analysis and structural equation modeling on five independent samples of about 300 subjects each confirmed the plausibility of this S-ART mindfulness manifold, suggesting a flow of influence from self-awareness over self-regulation to self-transcendence, and then outward to select aspects of psychological functioning, such as mood and wellbeing (Verhaeghen, 2019a), wisdom (Verhaeghen, 2019b), and ethical sensitivities (Verhaeghen, 2019b; Verhaeghen \& Aikman, 2020). Factor analysis revealed additional subdivisions within the components of self-awareness and self-regulation: Self-awareness incorporated reflective awareness (the more active, deliberate, probing aspect of mindfulness-akin to or perhaps synonymous with Morin's, 2018, concept of self-reflection) and controlled sense-ofself in the moment (the more passive, equanimous, nonjudgmental aspect of mindfulness); self-regulation was tapped by (the opposite of) self-preoccupation and by self-compassion (for more details, see the Methods section below).

This broader conceptualization of mindfulness allows us to further test the interconnectedness between inner speech, self-awareness, and self-regulation. If we accept the flow within S-ART as going from self-awareness (S-A) to selfregulation (S-R), then either self-awareness or inner speech (IS) or both may be the driver of individual differences in self-regulation, and the effects of one may or may not be mediated by the other. We will investigate these different configurations using hierarchical regression models. Our implementation of the S-ART model adds some possible nuance to the findings, given that it contains two sub-constructs each for the constructs of self-awareness and selfregulation, which allows for an examination of how the models generalize across related constructs. Moreover, including all three variables (i.e., IS, S-A, and S-R) allows for a more precise investigation into the role of inner speech per se. The literature suggests that inner speech fosters both self-awareness and self-regulation, and that self-awareness fosters self-regulation. If self-awareness and inner speech are intimately coupled, a three-variable approach is needed to disentangle the respective contributions of inner speech and self-awareness on self-regulation. It is important to note here that our conceptualization of self-awareness derives from the mindfulness literature, and as such may not overlap completely with the concept of self-awareness as operationalized in traditional inner speech studies.

A third possibility (apart from the standard view and the reverse view) is that adult inner speech might ultimately be an epiphenomenon, an ineffective vestige from development; we label this 'the epiphenomenon view'. That is, adults might no longer need or use inner speech to successfully self-regulate, except in extreme circumstances (such as a particularly taxing cognitive task), because self-awareness has taken over the self-regulatory aspect of inner speech. Finally, a fourth possibility is that inner speech and selfawareness are not directly related to each other, and each 
contribute independent variance to self-regulation; we label this 'the independence view'.

The data sets used here originate in two independent samples from Verhaeghen (2019b). Apart from measures of the mindfulness manifold and inner speech, these data sets also include measures of what can be considered two highlevel regulatory mechanisms, namely wisdom and ethical sensitivities. To the best of our knowledge, no data on inner speech and these high-level regulatory constructs exist.

What additionally makes these data sets interesting is the prior finding that self-awareness had differential relationships to each of the members within each pair of constructs, as follows (Verhaeghen, 2019b). Wisdom was factor-analyzed into two factors, one measuring wisdom about the self, tapped by scales often theorized to measure personal wisdom, the other measuring wisdom about the world, which taps more general knowledge about the (social) world. The former was related to self-awareness, the latter was not. Haidt's Moral Foundations Theory (MFT; Graham et al., 2013) provided the framework for examining ethical sensitivities. MFT posits that ethical sensitivities ultimately boil down to five dimensions: avoiding harm, fairness, ingroup loyalty, respect for authority, and purity. The former two can be combined into an 'individualizing' foundation, focusing on the provision and protection of individual rights; the remaining three into a 'binding' foundation, focusing on ingroup cohesion. We found that individualizing was related to self-awareness; binding was not (Verhaeghen, 2019b). These differential outcomes then allow an additional window into the interplay between inner speech and self-awareness: If they are as intimately coupled as assumed, we would expect inner speech to be associated with the higher-order aspects that self-awareness is associated with, and not with the others. Sample B additionally included a measure of psychological wellbeing; we will include this here as an additional dependent variable.

\section{Research overview}

In the present study, we investigate how inner speech is related to self-awareness and different aspects of self-regulation, examining four possible scenarios: (a) the standard view, which claims that inner speech is a precursor of selfawareness, (b) the reverse view, which states that selfawareness is a precursor of inner speech, (c) the epiphenomenon view, which states that inner speech is not effective in self-regulatory behavior, but self-awareness is, and (d) the independence view, which states that the inner speech and self-awareness each contribute independent variance to selfregulation.

\section{METHOD}

\section{Participants}

Participants $(n=433)$ were from two samples from Verhaeghen (2019b). Sample A consisted of 260 undergraduate students from the Georgia Institute of Technology, aged 18$26($ mean $=19.7, \mathrm{SD}=1.5) ; 54 \%$ were women. Sample B consisted of 173 participants recruited from Mechanical Turk $^{1}$, aged $21-74($ mean $=39.8$, SD $=11.7) ; 44 \%$ were women. Although Mechanical Turk is generally a useful, valid, and reliable tool for behavioral researchers (e.g., Mason \& Suri, 2012), we found it prudent to assess potential differences in data quality between the two samples by comparing Cronbach's alpha values for all subscales. Sample B (Mechanical Turk) tended to have higher reliability values (median $=.84$, ranging from .41 to .93$)$ than Sample A (students) $($ median $=.78$, ranging from .48 to .90$)$. The correlation between Fisher $z$-transformed reliability values between the samples was .74, suggesting that the groups were about equally sensitive to differences in the item characteristics that drive reliability. The two samples were pooled for all data analyses reported here, except the analysis on psychological wellbeing, where we only have data from Sample B.

\section{Measures and procedure}

Participants filled out all questionnaires online; they took about 45-60 minutes to complete for a total of 328 items. The mindfulness measures (i.e., self-awareness and selfregulation) were presented as they resulted from a set of factor analyses reported in Verhaeghen (2019a); this structure was replicated in Verhaeghen \& Aikman, 2020). Cronbach's alpha values are reported as found in the present sample. Note that some scales (notably the subscales of the Self-Compassion Scale) contain a very small number of items, possibly depressing the alpha values. For data reduction purposes and to examine the inherent structure in the data we conducted exploratory factor analysis (principal component analysis with oblimin rotation) on the inner speech items. Eigenvalues and the scree plot suggested a seven-factor solution, explaining $65 \%$ of the variance. This solution, however, had a first factor with a large number of items (viz., 14) and no simple interpretation. Extracting eight factors led to a more straightforwardly interpretable structure. This solution was retained here; it is shown in the Appendix, with items that had loadings of 0.40 or higher. The two items that showed crossloadings (SVQ22, SVQ7) were ascribed to the scale associated with the highest loading. All variables included in the regression analysis are listed in Table 1, which also contains their intercorrelations.

\section{Control variables}

As in Verhaeghen (2019b), control variables (age, gender, the Big Five personality trait factors, and social conservatism) were included in the models to purify the relationships between constructs. That is, some of the relationships between constructs might be due to the influence of underlying extraneous factors. For instance, in Verhaeghen (2019b), we found that the trait factor Openness to experience was related to both self-awareness and wisdom, and so, in order to tap into the true relationship between self-awareness and

\footnotetext{
${ }^{1}$ Mechanical Turk is a crowdsourcing platform, started and maintained by Amazon, aimed to connect 'workers' with 'requesters' to perform online tasks, such as filling out surveys, for a fee. Mechanical Turk workers needed to be highly qualified in order to participate- more than 5,000 Human Intelligence Tasks (i.e., surveys or other online tasks) completed, and at least $98 \%$ of those approved by the requester.
} 
Table 1. Correlation matrix for all relevant variables.

\begin{tabular}{|c|c|c|c|c|c|c|c|c|c|c|c|c|c|c|c|c|c|c|c|c|c|c|c|c|}
\hline Variables & 1 & 2 & 3 & 4 & 5 & 6 & 7 & 8 & 9 & 10 & 11 & 12 & 13 & 14 & 15 & 16 & 17 & 18 & 19 & 20 & 21 & 22 & 23 & 24 \\
\hline \multicolumn{25}{|l|}{1 Gender } \\
\hline 2 Age & $-16^{* *}$ & & & & & & & & & & & & & & & & & & & & & & & \\
\hline 3 Social conservatism & 01 & 05 & & & & & & & & & & & & & & & & & & & & & & \\
\hline \multicolumn{25}{|l|}{ Mini-IPIP } \\
\hline 4 Extraversion & 07 & $-20^{* *}$ & 05 & & & & & & & & & & & & & & & & & & & & & \\
\hline 5 Agreeableness & 02 & -01 & $17^{* * *}$ & $28^{* * *}$ & & & & & & & & & & & & & & & & & & & & \\
\hline 6 Conscientiousness & -03 & $20^{* *}$ & $17^{* *}$ & -01 & $20^{* *}$ & & & & & & & & & & & & & & & & & & & \\
\hline 7 Neuroticism & $14^{* *}$ & $-20^{* *}$ & -10 & $-20^{* *}$ & $-15^{* *}$ & $-29^{* *}$ & & & & & & & & & & & & & & & & & & \\
\hline 8 Intellect/imagination & -08 & 00 & -04 & $19^{* *}$ & $21^{* *}$ & 03 & $-15^{* *}$ & & & & & & & & & & & & & & & & & \\
\hline \multicolumn{25}{|l|}{ Inner Speech } \\
\hline 9 Action guidance & 03 & -09 & -04 & 08 & $10^{*}$ & -01 & $16^{* *}$ & 03 & & & & & & & & & & & & & & & & \\
\hline 10 Problem solving/search & 06 & $-16^{* *}$ & -03 & $14^{* *}$ & 09 & -06 & $14^{* *}$ & 02 & $78^{* *}$ & & & & & & & & & & & & & & & \\
\hline 11 Memory/attention regulation & 08 & $-16^{* *}$ & 01 & $12^{* *}$ & $20^{* *}$ & 01 & 08 & 07 & $69^{* *}$ & $63^{* *}$ & & & & & & & & & & & & & & \\
\hline 12 Emotion regulation & 08 & $-10^{*}$ & 07 & $10^{*}$ & 04 & -04 & $19^{* *}$ & 00 & $70^{* *}$ & $68^{* *}$ & $55^{* *}$ & & & & & & & & & & & & & \\
\hline 13 Evaluate/motivate & $12^{*}$ & $-18^{* *}$ & -01 & -06 & -03 & $-10^{*}$ & $22^{* *}$ & 03 & $34^{* *}$ & $28^{* *}$ & $32^{* *}$ & $33^{*}$ & & & & & & & & & & & & \\
\hline 14 Other voices & 06 & $-19^{* *}$ & -05 & 05 & -05 & $-14^{* *}$ & $16^{* *}$ & $-10^{*}$ & $22^{* * *}$ & $24^{* *}$ & 03 & $21^{* *}$ & $30^{* *}$ & & & & & & & & & & & \\
\hline 15 Inner dialogue & 05 & $-20^{* *}$ & -06 & 02 & 01 & -08 & $18^{* *}$ & $12^{*}$ & $33^{* *}$ & $29^{\text {** }}$ & $28^{* *}$ & $26^{* * *}$ & $61^{* *}$ & $34^{* *}$ & & & & & & & & & & \\
\hline 16 Condensed speech & 08 & -01 & 00 & 06 & -05 & $-11^{*}$ & $11^{*}$ & $-15^{* *}$ & -02 & 04 & $-14^{* * *}$ & -05 & -01 & $29^{* *}$ & -06 & & & & & & & & & \\
\hline \multicolumn{25}{|l|}{ Self-Awareness } \\
\hline 17 Reflective awareness & -04 & -08 & 05 & $17^{* *}$ & $35^{* *}$ & $16^{* *}$ & -04 & $38^{* *}$ & $28^{* *}$ & $24^{* *}$ & $28^{* *}$ & $22^{* *}$ & $20^{* *}$ & $10^{*}$ & $18^{* *}$ & -06 & & & & & & & & \\
\hline 18 Controlled sense-of-self in moment & -09 & $31^{* *}$ & 04 & $18^{* *}$ & $26^{* *}$ & $40^{* *}$ & $-59^{* *}$ & $14^{* *}$ & $-12^{*}$ & $-12^{*}$ & -03 & $-17^{* *}$ & $-39^{* *}$ & $-31^{* *}$ & $-30^{* *}$ & $-10^{*}$ & 03 & & & & & & & \\
\hline \multicolumn{25}{|l|}{ Self-regulation } \\
\hline 19 Self-preoccupation & $12^{*}$ & $-36^{* *}$ & 00 & $-17^{* *}$ & -07 & $-23^{* *}$ & $62^{* *}$ & $-14^{* *}$ & $19^{* *}$ & $16^{* *}$ & $23^{* *}$ & $20^{* *}$ & $37^{* *}$ & $22^{* *}$ & $27^{* *}$ & 02 & $11^{*}$ & $-60^{* *}$ & & & & & & \\
\hline 20 Self-compassion & 00 & $-27^{* *}$ & $13^{*}$ & $18^{* *}$ & $20^{* * *}$ & -01 & $-26^{* *}$ & 03 & $10^{*}$ & $15^{* *}$ & $15^{* *}$ & 05 & 00 & $10^{*}$ & 05 & -01 & $21^{* *}$ & 09 & -04 & & & & & \\
\hline \multicolumn{25}{|l|}{ Wisdom scales } \\
\hline 21 Wisdom about the self & -04 & 02 & $13^{*}$ & $32^{* *}$ & $45^{* *}$ & $19^{* *}$ & $-31^{* *}$ & $38^{* *}$ & $28^{* *}$ & $25^{* *}$ & $36^{* *}$ & $23^{* *}$ & $15^{* *}$ & 03 & $19^{* *}$ & -08 & $63^{* *}$ & $30^{* *}$ & $-15^{* *}$ & $33^{* *}$ & & & & \\
\hline 22 Wisdom about the world & 05 & -02 & -03 & $17^{* *}$ & $19^{* *}$ & 03 & -09 & 05 & -03 & -01 & 02 & -03 & 06 & -04 & 03 & 02 & $14^{* *}$ & 08 & -08 & $14^{* *}$ & $22^{* *}$ & & & \\
\hline \multicolumn{25}{|l|}{ Moral foundations } \\
\hline $23 \mathrm{MFQ}$ - individualizing & $21^{* *}$ & $-27^{* *}$ & 08 & $14^{* *}$ & $30^{* * *}$ & -03 & 09 & 05 & $12^{*}$ & $12^{*}$ & $25^{* *}$ & 09 & $24^{* *}$ & $11^{*}$ & $23^{* *}$ & -01 & $30^{* *}$ & -09 & $30^{* *}$ & $22^{* *}$ & $36^{* *}$ & $16^{* *}$ & & \\
\hline $24 \mathrm{MFQ}$ - binding & 00 & $-23^{* *}$ & $65^{* *}$ & $12^{*}$ & $14^{* *}$ & $10^{*}$ & 00 & $-14^{* *}$ & $10^{*}$ & $10^{*}$ & $12^{*}$ & $16^{* *}$ & $18^{\text {** }}$ & $16^{* * *}$ & $10^{*}$ & 04 & $15^{* *}$ & $-10^{*}$ & $20^{* *}$ & $23^{* *}$ & $22^{* * *}$ & 04 & $36^{\text {*** }}$ & \\
\hline \multicolumn{25}{|l|}{ Wellbeing } \\
\hline 25 Psychological wellbeing & $-15^{*}$ & 07 & $24^{* *}$ & $48^{* *}$ & $50^{* *}$ & $39^{* *}$ & $-70^{* *}$ & $21^{* *}$ & 11 & 05 & 11 & 05 & -08 & 06 & 00 & -02 & $42^{* *}$ & $62^{* *}$ & $-53^{* *}$ & $21^{* *}$ & $66^{* *}$ & 07 & $20^{* * *}$ & $25^{* *}$ \\
\hline
\end{tabular}

Note: $N=433$, except for correlations involving psychological wellbeing, where $n=173$; IPIP = International Personality Item Pool (ipip.ori.org); IS = Inner Speech; S-A = Self-Awareness; MFQ = Moral Foundations Questionnaire; * $p<05$; ** $p<01$. Second column gives Cronbach's alphas and numbers of items between brackets. Of the correlations, decimal points are omitted. 
wisdom about the self, the influence of openness needed to be partialed out.

The Mini-IPIP (Donnellan, Oswald, Baird, \& Lucas, 2006) is a 20-item measurement of the Big Five personality factors, 4 items for each factor: Extraversion (Cronbach's alpha $=.85)$, Agreeableness (Cronbach's alpha $=.81$ ), Conscientiousness (Cronbach's alpha $=.73)$, Openness $($ which the IPIP labels Intellect/Imagination; Cronbach's alpha = $.78)$, and Neuroticism (Cronbach's alpha $=.76)$. Social conservatism was included because it is typically highly correlated with the binding moral foundations (e.g., Haidt, 2012). It was measured via the Social Conservatism subscale (6 items, Cronbach's alpha $=.66$ ) of the Social and Economic Conservatism Scale (Everett, 2013). Additionally, participants were asked for their age and gender.

\section{Inner speech}

Two scales for inner speech were included, one focusing mainly on its phenomenology, the Varieties of Inner Speech Questionnaire (VISQ, McCarthy-Jones \& Fernyhough, 2011; 18 items; originally comprised of subscales for dialogic speech, condensed inner speech, other people in inner speech, and evaluative/motivational speech), the other mainly on its functionality, the Self-Verbalization Questionnaire (SVQ; Duncan \& Cheyne, 1999; 27 items; originally comprised of scales for spatial search, behavioral-organizational speech, cognitive-attentional speech, and affective speech). As mentioned above, factor analysis revealed eight subscales (Appendix). We constructed these by taking the mean of the scores of the respective items on the factors; the scales largely, but not completely correspond to the original subscales in the two surveys. We labeled the scales as problem solving/search (Cronbach's alpha $=.88$ ), action guidance (Cronbach's alpha $=.89$ ), memory/attention regulation (Cronbach's alpha $=.86$ ), emotion regulation (Cronbach's alpha $=.79)$, evaluate-motivate (Cronbach's alpha $=.79$ ), other voices (Cronbach's alpha $=.91$ ), inner dialogue (Cronbach's alpha $=.88$ ), and condensed speech (Cronbach's alpha $=.88$ ).

\section{Self-awareness}

Two constructs were assessed within self-awareness. The first, reflective awareness, is the unit-weighted composite of the $z$-scores of three scales: (a) the Observing subscale of the Five Facets Mindfulness Questionnaire (FFMQ; Baer et al., 2006) (8 items; Cronbach's alpha = .80); (b) the Reflectiveness subscale of the Broad Rumination Scale (BRS; Trani, Rubinsztain, \& Verhaeghen, in preparation) (4 items; Cronbach's alpha = .81); and (c) Search for Insight/Wisdom of the Aspects of Spirituality scale (Büssing, Ostermann, \& Matthiessen, 2007) (7 items; Cronbach's alpha $=.87$ ).

The second construct, controlled sense-of-self in the moment, is the unit-weighted composite of the $z$-scores of three scales: (a) the Acting with Awareness subscale from the FFMQ (8 items; Cronbach's alpha = .89); (b) the Sense-ofself Scale (Flury \& Ickes, 2007) (12 items; Cronbach's alpha $=.88)$; and $(c)$ the Nonjudging of inner experience subscale of the FFMQ ( 8 items; Cronbach's alpha $=.91$ ).

\section{Self-regulation}

Two constructs were assessed within self-regulation. The first, self-preoccupation, is the unit-weighted composite of the $z$-scores of two subscales from the BRS, namely Compulsivity $(5$ items; Cronbach's alpha $=.83)$ and Worrying $(3$ items; Cronbach's alpha $=.63$ ), as well as two subscales from the Self-Compassion Scale, Short Form (SCS; Raes, Pommier, Neff, \& Van Gucht, 2011), namely Isolation (2 items; Cronbach's alpha $=.68)$ and Over-Identified (2 items; Cronbach's alpha $=.71$ ).

The second, self-compassion, was measured as the unitweighted composite of the $z$-scores of three subscales from the SCS, namely Self-Kindness (2 items; Cronbach's alpha $=. .65)$, Common humanity (2 items; Cronbach's alpha = .58 ), and Mindfulness (2 items; Cronbach's alpha $=.74$ ), as well as the Decentering subscale of the Experiences Questionnaire (Fresco et al., 2007) (13 items; Cronbach's alpha $=.89)$.

\section{Moral foundations}

This construct was measured using the five subscales of the Moral Foundations Questionnaire (Graham et al., 2011): (a) Care/harm (6 items; Cronbach's alpha $=.56)$; (b) Fairness (6 items; Cronbach's alpha $=.58)$; (c) Ingroup loyalty (6 items; Cronbach's alpha $=.63)$; (d) Authority (6 items; Cronbach's alpha = .67); and (e) Purity (6 items; Cronbach's alpha $=.77)$. The two individualizing foundations were collapsed into a single construct, using a unit-weighted $z$-score composite (the correlation between the two individualizing foundations was .56); so were the three binding foundations (intercorrelations between the three binding foundations ranged from .64 to .70).

\section{Wisdom scales}

Two constructs were assessed within wisdom, as in Verhaeghen (2019b). The first, wisdom about the self, is the unitweighted composite of the $z$-scores of six scales: the selftranscendence scale from the Adult Self-Transcendence Inventory (Levenson et al., 2005; 10 items; Cronbach's alpha $=.73$ ) and the five subscales of the Self-Assessed Wisdom Scale (Webster, 2003), namely experience (8 items; Cronbach's alpha $=.82$ ), emotions ( 8 items; Cronbach's alpha $=.85)$, reminiscence $(8$ items; Cronbach's alpha $=.88)$, openness ( 8 items; Cronbach's alpha $=.88)$, and humor $(8$ items; Cronbach's alpha $=.76)$. The second wisdom construct, wisdom about the world is the unit-weighted z-composite of the three subscales of the Three-Dimensional Wisdom Scale (Ardelt, 2003), namely the cognitive (14 items; Cronbach's alpha $=.82)$, reflective (12 items; Cronbach's alpha $=.84)$, and affective subscale (13 items; Cronbach's alpha $=.79)$.

\section{Psychological wellbeing}

Four subscales of the Psychological Well-Being scale (PWB; Ryff \& Keyes, 1995) were included, each including 7 items: Personal Growth, Positive Relations, Purpose in Life, and Self-Acceptance. The sum of the subscales was used to create a total score (Cronbach's alpha $=.94)$.

\section{Order of presentation}

Scales were presented in this order: FFMQ, NAS, RS, SCS, EQ, SOSS, IPIP, BRS, ERQ, PWB, DPES, ASP, MFQ, SECS, VISQ, SVQ, ASTI, SAWS, 3D-WS, PWBS, demographics. All variables up until ASP have been used in all of our mindfulness studies, in that order. The outcome 
variables (MFQ, VISQ, SVQ, ASTI, SAWS, 3D-WS, PWBS) were next, with no strong rationale for their order. SECS was administered after MFQ because SECS has a strong correlation with MFQ, and activating those attitudes might influence MFQ scores. Demographics were presented last to avoid effects such as stereotype threat.

\section{RESULTS}

\section{Correlations}

The correlation matrix is presented in Table 1. To summarize the link between self-awareness and inner speech, we computed the median correlations between the two aspects of self-awareness and the eight aspects of inner speech: Reflective self-awareness had a median correlation of .20 with inner speech; for controlled sense-of-self in the moment, the median correlations with inner speech was -.14. Of the 56 correlations between aspects of inner speech and our dependent variables, 30 were significant; the median correlation was .10.

\section{Predicting self-preoccupation and self-compassion from inner speech and self-awareness}

To examine how self-awareness and inner speech are related to the aspects of self-regulation present in the S-ART model, hierarchical multiple regression analysis was applied to the data, with the two types of self-regulation (self-preoccupation and self-compassion) as the final outcome. The results are presented in Table 2. Background variables (personality, age, gender, and social conservatism were entered in Step 1; in Step 2 either inner speech (Step 2a) or self-awareness (Step 2b) were entered; Step 3 included all predictors (background variables, inner speech, and self-awareness). Thus, examining the difference between Step 3 and Step 2a indicates to what extent self-awareness predicts variance in the dependent variable over and above inner speech. Conversely, examining the difference between Step 3 and Step $2 \mathrm{~b}$ indicates to what extent inner speech awareness predicts variance in the dependent variable over and above selfawareness. This can help elucidating to what extent the effects of self-awareness are mediated by inner speech (as would be claimed in the standard model) or vice versa (as claimed in the reverse model), the extent to which inner speech explains any variance at all (as the epiphenomenon model claims it would not), or the extent to which both sets of variables would explain independent amounts of variance in self-regulation (as claimed by the independence model).

For self-preoccupation, in Step 2, after the background variables were entered, both inner speech (Step 2a) and selfawareness (Step 2b) explained a significant amount of variance; in Step 3, either construct added to the variance. In that third step, decreases in the value of the regression coefficients were noted for one of the inner speech variables (evaluate/motivate) and one of the self-awareness variables (reflective awareness). For self-compassion, the set of selfawareness variables added significant variance after the background variables were accounted for, whereas the set of inner speech variables did not.
Predicting wisdom, the moral foundations, and psychological wellbeing from inner speech and self-awareness

Tables 3-5 provide results from a series of hierarchical regression analyses to predict wisdom about the self, wisdom about the world, the individualizing moral foundation, the binding moral foundation, and psychological wellbeing. We found that both inner speech and self-awareness predicted these different dependent variables when entered after the background variables, with a few exceptions (wisdom about the world for inner speech and self-awareness, binding for self-awareness). When all variables were entered, inner speech was a significant predictor for wisdom about the self, individualizing, and binding; self-awareness was a significant predictor for wisdom about the self and individualizing. Within the inner speech variables, only memory/attention regulation (twice) and evaluate/motivate (once) ever showed significant effects; within self-awareness, both reflective awareness and controlled sense-of-self in the moment were significant predictors at least twice. Table 6 summarizes the main findings.

\section{DISCUSSION}

This study examined the relationship between inner speech, self-awareness, and self-regulation. Inner speech was assessed using two questionnaires, which ultimately yielded eight factor-analysis-derived subscales, covering both functional (action guidance, problem solving/search, memory/attention regulation, emotion regulation, and evaluate/motivate) and phenomenological aspects (other voices, inner dialogue, condensed speech) of inner speech. Selfawareness was examined under two aspects: the more active, deliberate, probing aspect of reflective awareness, and the more passive, equanimous, nonjudgmental aspect of controlled sense-of-self in the moment (Verhaeghen, 2019a, 2019b; Verhaeghen \& Aikman, 2020). Self-regulation was investigated under the guises of (the opposite of) self-preoccupation and of self-compassion (ibidem). We also examined the influence of inner speech and self-awareness on higher-order measures of regulation-wisdom and ethical sensitivities-and on psychological wellbeing.

\section{The relationship between inner speech and self-aware- ness}

A first finding, obtained at the level of correlations, is that the two aspects of self-awareness had opposite-signed and significant correlations with inner speech (with the single exception of condensed speech, which had a $n s$ connection with reflective awareness). Reflective awareness most often showed positive correlations, which were significant in seven out of eight cases (the exception being condensed speech) (see row 17 and columns 9-16 in Table 1). Correlations between reflective awareness and the functional aspects of inner speech (i.e., action guidance, problem solving/search, memory/attention regulation, emotion regulation, and evaluate/motivate) were all significant, suggesting that individuals who are more self-reflective, or more actively mindful, use inner speech more often for functional purposes. This is what we expected from the literature as 
Table 2. Results of hierarchical regression predicting self-preoccupation and self-compassion

\begin{tabular}{|c|c|c|c|c|}
\hline & $\begin{array}{c}\text { Step 1: } \\
\text { Covariates }\end{array}$ & $\begin{array}{c}\text { Step 2a: } \\
\text { Covariates, IS }\end{array}$ & $\begin{array}{c}\text { Step 2b: } \\
\text { Covariates, S-A }\end{array}$ & $\begin{array}{c}\text { Step 3: } \\
\text { Covariates, IS, S-A }\end{array}$ \\
\hline & \multicolumn{4}{|c|}{ Self-preoccupation } \\
\hline Gender & .000 & -.001 & .001 & .000 \\
\hline Age & $-.026 * * *$ & $-.022 * * *$ & $-.019 * * *$ & $-.017 * * *$ \\
\hline Social conservatism & .007 & .007 & .004 & .004 \\
\hline \multicolumn{5}{|l|}{ Mini-IPIP } \\
\hline Extraversion & $-.013 * *$ & $-.012 * *$ & $-.010^{*}$ & -.009 \\
\hline Agreeableness & .005 & .002 & .006 & .004 \\
\hline Conscientiousness & -.001 & -.002 & .003 & .003 \\
\hline Neuroticism & $.056 * * *$ & $.051 * * *$ & $.039 * * *$ & $.038 * * *$ \\
\hline Intellect/imagination & -.004 & -.007 & $-.009 *$ & $-.009 *$ \\
\hline \multicolumn{5}{|l|}{ Inner Speech } \\
\hline Action guidance & & -.003 & & -.004 \\
\hline Problem solving/search & & -.007 & & -.008 \\
\hline Memory/attention regulation & & $.020 * *$ & & $.022 * * *$ \\
\hline Emotion regulation & & .000 & & .000 \\
\hline Evaluate/motivate & & $.017 * *$ & & .007 \\
\hline Other voices & & .007 & & .005 \\
\hline Inner dialogue & & .000 & & .000 \\
\hline Condensed speech & & -.002 & & -.002 \\
\hline \multicolumn{5}{|l|}{ Self-Awareness } \\
\hline Reflective awareness & & & $.013 * *$ & .007 \\
\hline Controlled sense-of-self in the moment & & & $-.034 * * *$ & $-.031 * * *$ \\
\hline$R^{2}$ & .48 & .54 & .56 & .59 \\
\hline$R^{2}$ change (for final row: Step 2a-3) & $.48 * * *$ & $.06 * * *$ & & $.05 * * *$ \\
\hline \multirow[t]{2}{*}{$R^{2}$ change (for final row: Step $2 \mathrm{~b}-3$ ) } & $.48 * * *$ & & $.08 * * *$ & $.04 * * *$ \\
\hline & \multicolumn{4}{|c|}{ Self-compassion } \\
\hline Gender & -.004 & -.004 & -.003 & -.002 \\
\hline Age & $-.032 * * *$ & $-.030 * * *$ & $-.031 * * *$ & $-.029 * * *$ \\
\hline Social conservatism & $.010 *$ & $.012 *$ & $.010 *$ & $.011 *$ \\
\hline \multicolumn{5}{|l|}{ Mini-IPIP } \\
\hline Extraversion & -.001 & -.002 & -.002 & -.003 \\
\hline Agreeableness & $.015 * *$ & $.013 *$ & .011 & .010 \\
\hline Conscientiousness & -.007 & -.007 & $-.011 *$ & -.011 \\
\hline Neuroticism & $-.030 * * *$ & $-.031 * * *$ & $-.031 * * *$ & $-.031 * * *$ \\
\hline Intellect/imagination & -.001 & -.001 & -.007 & -.007 \\
\hline \multicolumn{5}{|l|}{ Inner Speech } \\
\hline Action guidance & & .004 & & .003 \\
\hline Problem solving/search & & .011 & & .011 \\
\hline Memory/attention regulation & & .004 & & .002 \\
\hline Emotion regulation & & -.007 & & -.008 \\
\hline Evaluate/motivate & & -.007 & & -.010 \\
\hline Other voices & & .006 & & .005 \\
\hline Inner dialogue & & .004 & & .005 \\
\hline Condensed speech & & .001 & & .001 \\
\hline \multicolumn{5}{|l|}{ Self-Awareness } \\
\hline Reflective awareness & & & $.018 * *$ & $.017 * *$ \\
\hline Controlled sense-of-self in the moment & & & .002 & .000 \\
\hline$R^{2}$ & .20 & .23 & & .24 \\
\hline$R^{2}$ change (for final row: Step 2a-3) & $.20 * * *$ & .03 & & $.02 *$ \\
\hline$R^{2}$ change (for final row: Step 2b-3) & $.20 * * *$ & & $.02 * *$ & .02 \\
\hline
\end{tabular}


Table 3. Results of hierarchical regression predicting wisdom about the self and wisdom about the world

\begin{tabular}{|c|c|c|c|c|}
\hline & $\begin{array}{c}\text { Step 1: } \\
\text { Covariates }\end{array}$ & $\begin{array}{c}\text { Step 2a: } \\
\text { Covariates, IS }\end{array}$ & $\begin{array}{c}\text { Step 2b: } \\
\text { Covariates, S-A }\end{array}$ & $\begin{array}{c}\text { Step 3: } \\
\text { Covariates, IS, S-A }\end{array}$ \\
\hline & \multicolumn{4}{|c|}{ Wisdom about the self } \\
\hline Gender & -.003 & -.004 & .000 & -.001 \\
\hline Age & .004 & .008 & .005 & .006 \\
\hline Social conservatism & .005 & .005 & .005 & .006 \\
\hline \multicolumn{5}{|l|}{ Mini-IPIP } \\
\hline Extraversion & $.013 * *$ & $.012 * *$ & $.010 *$ & .008 \\
\hline Agreeableness & $.031 * * *$ & $.027 * * *$ & $.018 * * *$ & $.016^{* * *}$ \\
\hline Conscientiousness & $.011 *$ & $.010 *$ & -.003 & -.003 \\
\hline Neuroticism & $-.017 * * *$ & $-.024 * * *$ & $-.015^{* *}$ & $-.017 * * *$ \\
\hline Intellect/imagination & $.031 * * *$ & $.028 * * *$ & $.014 * *$ & $.014 * *$ \\
\hline \multicolumn{5}{|l|}{ Inner Speech } \\
\hline Action guidance & & .002 & & .000 \\
\hline Problem solving/search & & -.004 & & -.003 \\
\hline Memory/attention regulation & & $.019 * *$ & & $.013 *$ \\
\hline Emotion regulation & & .008 & & .007 \\
\hline Evaluate/motivate & & .009 & & .008 \\
\hline Other voices & & .001 & & .000 \\
\hline Inner dialogue & & .006 & & $.009 *$ \\
\hline Condensed speech & & .007 & & .006 \\
\hline \multicolumn{5}{|l|}{ Self-Awareness } \\
\hline Reflective awareness & & & $.047 * * *$ & $.040 * * *$ \\
\hline Controlled sense-of-self in the moment & & & $.013 * *$ & $.019 * * *$ \\
\hline$R^{2}$ & .42 & .50 & .55 & .62 \\
\hline$R^{2}$ change (for final row: Step 2a-3) & $.42 * * *$ & $.09 * * *$ & & $.11 * * *$ \\
\hline \multirow[t]{2}{*}{$R^{2}$ change (for final row: Step 2b-3) } & $.42 * * *$ & & $.15^{* * * *}$ & $.05 * * *$ \\
\hline & \multicolumn{4}{|c|}{ Wisdom about the world } \\
\hline Gender & .004 & .002 & .004 & .002 \\
\hline Age & .000 & .000 & .001 & .001 \\
\hline Social conservatism & -.008 & -.010 & -.009 & -.010 \\
\hline \multicolumn{5}{|l|}{ Mini-IPIP } \\
\hline Extraversion & .010 & .012 & .011 & .012 \\
\hline Agreeableness & $.019 * *$ & $.020 * *$ & $.019 * *$ & $.019 * *$ \\
\hline Conscientiousness & -.001 & .000 & .000 & .000 \\
\hline Neuroticism & -.009 & -.008 & -.011 & -.009 \\
\hline Intellect/imagination & .003 & .003 & .002 & .001 \\
\hline \multicolumn{5}{|l|}{ Inner Speech } \\
\hline Action guidance & & -.013 & & -.013 \\
\hline Problem solving/search & & .000 & & .000 \\
\hline Memory/attention regulation & & -.001 & & -.001 \\
\hline Emotion regulation & & .002 & & .002 \\
\hline Evaluate/motivate & & .012 & & .010 \\
\hline Other voices & & -.007 & & -.007 \\
\hline Inner dialogue & & .000 & & .000 \\
\hline Condensed speech & & .002 & & .002 \\
\hline \multicolumn{5}{|l|}{ Self-Awareness } \\
\hline Reflective awareness & & & .002 & .003 \\
\hline Controlled sense-of-self in the moment & & & -.006 & -.003 \\
\hline$R^{2}$ & .08 & .10 & .08 & .10 \\
\hline$R^{2}$ change (for final row: Step 2a-3) & $.08^{* *}$ & .02 & & .00 \\
\hline$R^{2}$ change (for final row: Step $2 \mathrm{~b}-3$ ) & $.08^{* *}$ & & .00 & .02 \\
\hline
\end{tabular}


Table 4. Results of hierarchical regression predicting the individualizing and binding moral foundations

\begin{tabular}{|c|c|c|c|c|}
\hline & $\begin{array}{c}\text { Step 1: } \\
\text { Covariates }\end{array}$ & $\begin{array}{c}\text { Step 2a: } \\
\text { Covariates, IS }\end{array}$ & $\begin{array}{c}\text { Step 2b: } \\
\text { Covariates, S-A }\end{array}$ & $\begin{array}{c}\text { Step 3: } \\
\text { Covariates, IS, S-A }\end{array}$ \\
\hline & \multicolumn{4}{|c|}{ Individualizing } \\
\hline Gender & $.013 * *$ & $.012 *$ & $.015 * *$ & $.013 * *$ \\
\hline Age & $-.028 * * *$ & $-.024 * * *$ & $-.025 * * *$ & $-.023 * * *$ \\
\hline Social conservatism & .005 & .005 & .004 & .005 \\
\hline \multicolumn{5}{|l|}{ Mini-IPIP } \\
\hline Extraversion & -.002 & -.001 & -.002 & -.001 \\
\hline Agreeableness & $.029 * * *$ & $.025 * * *$ & $.025 * * *$ & $.023 * * *$ \\
\hline Conscientiousness & .001 & .000 & -.002 & -.002 \\
\hline Neuroticism & .005 & .003 & -.001 & .000 \\
\hline Intellect/imagination & .008 & .004 & .001 & -.001 \\
\hline \multicolumn{5}{|l|}{ Inner Speech } \\
\hline Action guidance & & -.005 & & -.006 \\
\hline Problem solving/search & & -.005 & & -.005 \\
\hline Memory/attention regulation & & $.024 * *$ & & $.023^{* *}$ \\
\hline Emotion regulation & & -.010 & & -.011 \\
\hline Evaluate/motivate & & .012 & & .008 \\
\hline Other voices & & -.001 & & -.002 \\
\hline Inner dialogue & & .007 & & .008 \\
\hline Condensed speech & & .001 & & .001 \\
\hline \multicolumn{5}{|l|}{ Self-Awareness } \\
\hline Reflective awareness & & & $.019 * *$ & $.016^{* *}$ \\
\hline Controlled sense-of-self in the moment & & & -.009 & -.006 \\
\hline$R^{2}$ & .21 & .27 & .24 & .29 \\
\hline$R^{2}$ change (for final row: Step 2a-3) & $.21 * * *$ & $.06 * *$ & & $.02 *$ \\
\hline \multirow[t]{2}{*}{$R^{2}$ change (for final row: Step 2b-3) } & $.21 * * *$ & & $.03 * *$ & $.05 * *$ \\
\hline & \multicolumn{4}{|c|}{ Binding } \\
\hline Gender & $-.011 * *$ & $-.011 * *$ & $-.010^{* *}$ & $-.011 * *$ \\
\hline Age & $-.025 * * *$ & $-.023 * * *$ & $-.022 * * *$ & $-.022 * * *$ \\
\hline Social conservatism & $.067 * * *$ & $.066 * * *$ & $.065 * * *$ & $.066 * * *$ \\
\hline \multicolumn{5}{|l|}{ Mini-IPIP } \\
\hline Extraversion & .003 & .004 & .004 & .004 \\
\hline Agreeableness & -.001 & -.001 & .000 & .000 \\
\hline Conscientiousness & $.011 * *$ & $.011 * *$ & $.014 * *$ & $.013 * *$ \\
\hline Neuroticism & .008 & .004 & .001 & .001 \\
\hline Intellect/imagination & -.003 & -.005 & -.004 & -.004 \\
\hline \multicolumn{5}{|l|}{ Inner Speech } \\
\hline Action guidance & & .006 & & .006 \\
\hline Problem solving/search & & -.004 & & -.004 \\
\hline Memory/attention regulation & & .000 & & .001 \\
\hline Emotion regulation & & .001 & & .001 \\
\hline Evaluate/motivate & & $.015^{* *}$ & & $.013 *$ \\
\hline Other voices & & .001 & & .001 \\
\hline Inner dialogue & & .001 & & .001 \\
\hline Condensed speech & & .002 & & .002 \\
\hline \multicolumn{5}{|l|}{ Self-Awareness } \\
\hline Reflective awareness & & & .003 & -.001 \\
\hline Controlled sense-of-self in the moment & & & $-.014 * *$ & -.008 \\
\hline$R^{2}$ & .51 & .54 & .52 & .54 \\
\hline$R^{2}$ change (for final row: Step 2a-3) & $.51 * * *$ & $.03 * *$ & & .00 \\
\hline$R^{2}$ change (for final row: Step 2b-3) & $.51 * * *$ & & $.01 *$ & .02 \\
\hline
\end{tabular}


Table 5. Results of hierarchical regression predicting psychological wellbeing (Sample B only)

\begin{tabular}{|c|c|c|c|c|}
\hline & $\begin{array}{c}\text { Step 1: } \\
\text { Covariates }\end{array}$ & $\begin{array}{c}\text { Step 2a: } \\
\text { Covariates, IS } \\
\end{array}$ & $\begin{array}{c}\text { Step 2b: } \\
\text { Covariates, S-A }\end{array}$ & $\begin{array}{c}\text { Step 3: } \\
\text { Covariates, IS, S-A } \\
\end{array}$ \\
\hline & \multicolumn{4}{|c|}{ Psychological Wellbeing } \\
\hline Gender & $-.013 *$ & $-.014 *$ & -.009 & $-.011 *$ \\
\hline Age & -.004 & -.002 & -.003 & -.003 \\
\hline Social conservatism & $.012 *$ & $.011 *$ & $.015 * *$ & $.014 * *$ \\
\hline \multicolumn{5}{|l|}{ Mini-IPIP } \\
\hline Extraversion & $.021 * * *$ & $.017 *$ & $.017 * *$ & $.014 * *$ \\
\hline Agreeableness & $.019 * *$ & $.016^{*}$ & $.012 *$ & .011 \\
\hline Conscientiousness & .009 & .010 & -.002 & -.002 \\
\hline Neuroticism & $-.049 * * *$ & $-.055 * * *$ & $-.039 * * *$ & $-.041 * * *$ \\
\hline Intellect/imagination & .003 & .004 & -.008 & -.007 \\
\hline \multicolumn{5}{|l|}{ Inner Speech } \\
\hline Action guidance & & .009 & & .005 \\
\hline Problem solving/search & & -.003 & & .000 \\
\hline Memory/attention regulation & & .001 & & -.005 \\
\hline Emotion regulation & & .005 & & .007 \\
\hline Evaluate/motivate & & -.004 & & .003 \\
\hline Other voices & & .010 & & .009 \\
\hline Inner dialogue & & .002 & & .000 \\
\hline Condensed speech & & .008 & & .009 \\
\hline \multicolumn{5}{|l|}{ Self-Awareness } \\
\hline Reflective awareness & & & $.025 * * *$ & $.022 * * *$ \\
\hline Controlled sense-of-self in the moment & & & $.026 * * *$ & $.031 * * *$ \\
\hline$R^{2}$ & .64 & .68 & .71 & .74 \\
\hline$R^{2}$ change (for final row: Step 2a-3) & $.64 * * *$ & .03 & & $.06^{* * *}$ \\
\hline$R^{2}$ change (for final row: Step $2 \mathrm{~b}-3$ ) & $.64 * * *$ & & $.07 * * *$ & .03 \\
\hline
\end{tabular}

reviewed in the Introduction. This replication is important, because it shows that our measures, atypical as they are on the self-awareness side, did show the same pattern of correlations as previously obtained in the literature.

Controlled sense-of-self in the moment, in contrast, showed negative correlations with inner speech, significant for seven out of eight cases (the exception was memory/attention regulation) (see row 18 and columns 9-16 in Table 1). For the functional aspects, this might suggest a trade-off, in the sense that individuals tend to be either observant about their reality or engaged in inner speech, maybe in the same way that outward-facing attention and the activity of the self-focused default mode network trade off within individuals. The correlations concerning the phenomenology of inner speech suggest that inner speech is more similar to external speech (i.e., heard/spoken in one's own voice, monologic, and extended) for individuals who tend to be more passively mindful or self-aware in the moment. As far as we know, this is a novel finding. The reason for the relationship is unclear, but one plausible explanation could be that thinking more often in extended inner language makes it easier for such speech to be detected, thus making people who have these thinking patterns more aware of their inner world.

Inner speech and self-awareness as predictors of selfpreoccupation and self-compassion

At the level of correlations, inner speech and self-regulation were related: 11 out of 16 correlations between inner speech and the two aspects of self-regulation from the S-ART model (i.e., self-preoccupation and self-compassion) were significant; the median correlation was .15. Our research question, however, concerns whether those relationships would survive regression analyses where we controlled for background variables and self-awareness.

Examining the regression analyses predicting self-regulation (see Table 2), we note a different pattern for self-preoccupation and self-compassion. In self-preoccupation, in Step 2, after the background variables were entered, both inner speech (Step 2a) and self-awareness (Step 2b) explained an equivalent and significant amount of variance; in Step 3, either construct added to the variance. In that third step, decreases in the value of the regression coefficients were noted for one of the inner speech variables (evaluate/motivate) and one of the self-awareness variables (reflective awareness). This suggests a certain independence in the influence between the two concepts, with a possible confluence or mutual mediation between the influences of evaluate/motivate and reflective self-awareness. Equally important, however, is to examine the direction of influence. The one aspect of self-awareness that remained significant in the final model (controlled sense-of-self in the moment) had a negative influence, indicating that people who are more passively aware of their inner states are less self-preoccupied. In contrast, the one aspect of inner speech that was significant in the final model (viz., memory/attention regulation) had a positive influence, implying that individuals who use inner speech to regulate their memory and attention are more self-preoccupied, rather than less. Self-pre- 
occupation is typically related to negative outcomes (in the present study, for instance, it is negatively correlated with wellbeing). Therefore, rather than indicating effective control, the latter result suggests a breakdown of control guided by inner speech.

For self-compassion, the set of self-awareness variables added significant variance after the background variables were accounted for, whereas the set of inner speech variables did not. From Step 3, we learned that self-awareness explained additional variance in self-compassion over and beyond inner speech, but inner speech did not explain selfcompassion over and beyond self-awareness. The effects of self-awareness were not mediated through inner speech, as indicated by the trivial drop in the value of the regression coefficient for reflective awareness in Step 2b when inner speech was added in Step 3. This suggests that inner speechwhether measured as a function or as a phenomenon-is not a predictor of self-compassion.

Our regression analyses also uncovered a possible role for personality in creating potentially spurious correlations between inner speech and self-regulation. The raw correlations between inner speech and self-preoccupation were all positive, with a median correlation of .21 . In the regression analyses, however, only inner speech used for memory/attention regulation and to evaluate/motivate showed a significant effect over and beyond that of the background variables, suggesting that the background variables play a role in creating the correlation for the remaining inner speech variables. Notably (and unsurprisingly, e.g., Nola, Roberts, \& Gotlib, 1998), neuroticism was a strong determinant of selfpreoccupation, and neuroticism also showed positive correlations with a number of inner speech variables. We think this finding is important for the methodology of future studies of inner speech and for the interpretation of extant studies, which more often than not do not control for personality variables. The end result may be that such studies may be mistaking personality-driven correlations between inner speech and self-regulation for substantive covariation.

\section{Inner speech and self-awareness as predictors of wis-} dom, moral foundations, and psychological wellbeing

With regard to the higher-order regulatory variables (wisdom and the moral foundations), we expected some variability-in our previous work two of the four aspects investigated (wisdom about the self and the individualizing moral foundation) were associated with self-awareness; the other two (wisdom about the world and the binding foundation) were not. If inner speech and self-awareness are as intimately coupled as assumed in the literature, we would expect inner speech to be associated with the higher-order aspects that self-awareness was associated with, and not with the others. Tables 3-6 provide the results in detail. There was evidence at the correlational level that inner speech and the five aspects of self-regulation discussed in this section are related: 19 out of 40 correlations were significant; the median correlation was .10. Again, the true test lies in the regression analyses.

For those aspects of higher-order self-regulation that were associated with self-awareness (wisdom about the self, individualizing, and binding), entering inner speech into the regression in Step 2a, after the background variables, led to modest but significant amounts of additional variance predicted over and above the background variables $\left(R^{2}\right.$ change between .03 and .09); entering self-awareness in a third step added between .00 and .11 to the explained variance, significant in two out of three cases. Reflective awareness was a significant predictor in two out of three cases after controlling for inner speech; controlled sense-of-self in the moment was significant after controlling for inner speech in one out of three cases. These results suggest that self-awareness has effects on wisdom about the self and individualizing over and beyond those of inner speech. Entering self-awareness in Step 2b, after the background variables, likewise led to modest but significant amounts of additional variance predicted over and above the background variables $\left(R^{2}\right.$ change between .01 and .15); entering inner speech in a third step added between $.02-.05$ to the explained variance, significant in two out of three cases. From the eight inner speech scales, only memory/attention regulation (two out of three cases) and evaluate/motivate (one out of three cases) were significant predictors after accounting for self-awareness. Taking these results together, it seems fair to conclude that selfawareness, especially under its guise of reflective awareness, is the true variable of import here, and inner speech has a more modest contribution.

For the one aspect not associated with self-awareness (wisdom about the world), no significant changes in variance accounted for were associated with entering inner speech in any of the steps.

Self-awareness, in both guises, was a significant predictor for psychological wellbeing, but none of the inner speech variables were.

\section{CONCLUSIONS}

The findings from all seven regression analyses are summarized in Table 6. Looking at the relative predictive power of self-awareness and inner speech in the models after controlling for the background variables, self-awareness is the more consistent predictor of self-regulation and psychological wellbeing (six out of seven cases for self-awareness vs. four out of seven for inner speech, with one of those effects in the opposite direction than predicted), although the amount of variance explained $(5.5 \%$ vs. $4.6 \%)$ is not all that different. When all variables are controlled for, self-awareness explains a significant amount of variance over and beyond inner speech in five out of seven cases, whereas inner speech explains a significant amount of variance over and beyond awareness in three out of seven cases, with one of those in the opposite direction than predicted. Again, the amount of unique variance explained does not differ much: $3.6 \%$ for self-awareness and $3.2 \%$ for inner speech.

A second important finding is that most aspects of inner speech did not reliably predict any of the criterion variables, with the exception of memory/attention regulation (significant in three cases, including one where the effect goes in the direction opposite the hypothesis), and evaluate/motive (one case). The influence of memory/attention regulation is an interesting finding, because the items in this scale clearly point to the habit of thinking out loud when memorizing or problem solving. Its relationship to wisdom about oneself and the moral foundation of individualizing suggests that these higher-order self-regulation processes might require 
Table 6. Summary of regression analyses predicting the seven variables of interest from background variables (gender, age, Big-Five personality factors), inner speech and self-awareness

\begin{tabular}{|c|c|c|c|}
\hline $\begin{array}{l}\text { Unique propor- } \\
\text { tion of variance } \\
\text { associated with } \\
\text { inner speech } \\
\text { variables over } \\
\text { and beyond } \\
\text { background var- } \\
\text { iables }\end{array}$ & $\begin{array}{l}\text { Unique pro- } \\
\text { portion of var- } \\
\text { iance associ- } \\
\text { ated with in- } \\
\text { ner speech } \\
\text { variables over } \\
\text { and beyond } \\
\text { background } \\
\text { and self- } \\
\text { awareness } \\
\text { variables }\end{array}$ & $\begin{array}{l}\text { Unique propor- } \\
\text { tion of vari- } \\
\text { ance associated } \\
\text { with self- } \\
\text { awareness var- } \\
\text { iables over and } \\
\text { beyond back- } \\
\text { ground varia- } \\
\text { bles }\end{array}$ & $\begin{array}{l}\text { Unique propor- } \\
\text { tion of variance } \\
\text { associated with } \\
\text { self-awareness } \\
\text { variables over } \\
\text { and beyond } \\
\text { background and } \\
\text { inner speech } \\
\text { variables }\end{array}$ \\
\hline
\end{tabular}

Criterion

\section{Self-Regulation}

\section{Self-preoccupation} $\begin{array}{ll}.06 * * * & .04 * * * \\ \text { (direction of ef- } & \text { (direction of } \\ \text { fect against hy- } & \text { effect against } \\ \text { pothesis) } & \text { hypothesis) }\end{array}$

Self-compassion pothesis) hypothesis)

\section{Wisdom Scales}

$\begin{array}{ll}.03 & .02\end{array}$

$.08 * * *$

$.05 * * *$ Inner speech variables significant in Self-awareness variables significant in

$.05 * * *$

$.02 * *$

$.02 *$

final model

final model

Wisdom about the world

$.09 * * *$

.02

$.15^{* * * *}$

$.11 * * *$

Moral Foundation

Individualizing

.02

.00

.00

$.03 * *$

$.02 *$

Binding

$.06 * *$

$.05^{* *}$

Well-Being

$.03 * * \quad .02$

Psychological wellbeing

.03

.03

$.07 * * *$

$.06 * * *$

Memory/attention regulation (direction of effect against hypothesis) Note: $N=433$, except for psychological wellbeing, $n=173$ IPIP = International Personality Item Pool (ipip.ori.org); IS = Inner Speech; S-A = Self-Awareness; * $p<05 ; * * p<01 ; * * * p<001$

Memory/attention regulation

(none)

Memory/attention regulation Evaluate/motivate

(none)
Controlled sense-of-self in the moment

Reflective awareness

Reflective awareness; controlled senseof-self in the moment

(none)

Reflective awareness

(none)

Reflective awareness; controlled sense- 
(or at least involve) habitual access to the deliberate, rational thinking system. Other studies (e.g., Garvey \& Ford, 2014) have noted that a preference for rational thinking predicts an emphasis on the individualizing foundation. This interpretation is also in line with our finding that reflective self-awareness is a predictor of the individualizing (but not binding) foundation. Interestingly, we found that habitual deployment of this system was also associated with higher levels of self-preoccupation, which is typically considered to be a maladaptive stance (e.g., Nolen-Hoeksema, 1991), as can also be seen here in the strong negative correlation between self-preoccupation and psychological wellbeing. Thus, this aspect of inner speech can have both positive and negative consequences. Evaluate/motivate was a significant predictor for the moral foundation not predicted by memory/attention regulation, namely binding. One possible explanation is that the items in the evaluate/motivate scale have a self-control flavor to them, and self-control is one aspect of self-regulation that people generally associate with the binding moral foundations (Mooijman et al., 2018).

On a slightly more general level, we note here that the finding that endorsement of the moral foundations is associated with select aspects of inner speech is interesting, given the often-made claim that the foundations are moral intuitions (e.g., Haidt, 2012). The intuition view implies that moral decisions are or can be made without recourse to deliberate thinking. Our results suggest the opposite, namely that people who habitually use inner speech for the purpose of memory/attention regulation or to evaluate/motivate themselves are more likely to be sensitive to issues of care and fairness (in the former case) or loyalty, authority, and purity (in the latter). This may imply either that habitual speech might be the source of the crystallization of moral attitudes into intuitions or that deliberate inner speech is involved in making online moral decisions after all, or both. Further research to disentangle these two possibilities might prove useful.

A third notable finding is that for the most part, but not always, variables that were significant in Step 2 remained significant in Step 3 (the analysis for binding is the exception). Typically, there is also some attenuation in the amount of variance explained by inner speech or self-awareness when adding the opposing set. Taken together, this suggests that the two sets of variables are partial mediators for each other, but with a clear degree of mutual independence.

Returning to our main question of the interconnectedness between inner speech, self-awareness, and self-regulation, our data at first approximation might suggest an independence model: both inner speech and self-awareness contribute to self-regulation independently, be it with evidence of some mutual partial meditation. However, it seems fairer to note that self-awareness, especially under its guise of reflective awareness, is the true variable of import here, and that inner speech has a more modest contribution. To wit, only two out of the eight inner speech variables ever reached significance in the final steps of the regression models, and in one of those cases, the relationship ran against the premise that these influences would be beneficial. The standard model and its reverse fare less well, given (a) that the two sets of variables are at least partially independent, and (b) that the regression analyses suggest symmetrical mediation effects rather than one set of variables being the clear mediator for the other. Our conclusion is that with regard to six of the inner speech variables, there is clear evidence for an epiphenomenon model, and for the remaining two (memory/attention regulation and evaluate/motivate), there is cautious support for an independence model. To answer the question in the title: Most of the time when we are talking to ourselves, nobody is listening, at least not in the sense that this inner talk has self-regulatory consequences over and beyond those of self-awareness.

\section{Caveats and limitations}

We are careful to point out that our results have to be taken in context. We are explicitly not claiming that inner speech (apart from memory/attention regulation and evaluate/motivate, under the circumstances described above) is never or under no circumstances helpful over and beyond self-awareness. There is, for instance, a broad literature on the effects of concurrent inner speech on aspects of executive control, including task switching (e.g., Emerson \& Miyake, 2003; Karbach \& Kray, 2007). Our operationalizations of self-regulation are, of course, much more general and high-level compared with those of most studies that have shown inner speech to be beneficial-there is quite a difference between telling yourself to turn the screw clockwise to tighten it versus instructing yourself to be kind to yourself or to not get caught up in a negative thought pattern, or to engage your personal inner wisdom. It can, however, also be argued that in the grand scheme of things the latter type of self-regulation presumably matters more.

A second important point is that our sample consisted of adults. It remains quite possible that the situation might be different in earlier stages of development, where even highlevel aspects of self-regulation might initially be under control of inner speech, as perhaps hinted at by the link between habitual inner speech and wisdom and the moral foundations.

Finally, our study examines the relationship between habitual patterns of inner speech and habitual patterns of selfregulation, unlike the studies that look at inner speech inthe-moment, connecting to a cognitive task in-the-moment. It is possible that high-level tasks using a tighter coupling of time scales might have revealed different results.

Our study has clear limitations. While mediational analysis can be applied to cross-sectional data, as we did here, only longitudinal work can truly assess causal relationships. The study was also limited by the actual scales and questionnaires used. We used self-awareness measures that fit within our conceptualization of mindfulness, and our selfregulation measures were likewise broader than is typical. Other measures of inner speech might have led to different results. It is quite possible that a more direct, in-the-moment measurement of inner speech and a more direct, in-the-moment measurement of self-awareness and self-regulation would have boosted correlations. At the same time, we point out that any strong theory or set of empirical findings should survive an alternative conceptualization or operationalization of its constructs. 


\section{ACCOUNTS AND ACKNOWLEDMENTS}

\section{Conflict of interest}

The authors have no conflicts of interest to declare.

\section{Data}

Data can be found at: https://osf.io/k8jbc/?view_only=506d280fee19408489a433 7f $21 \mathrm{f} 4 \mathrm{e} 188$

\section{REFERENCES}

Alderson-Day, B., \& Fernyhough, C. (2015). Inner speech: Development, cognitive functions, phenomenology, and neurobiology. Psychological Bulletin, 141, 931-965.

Ardelt, M. (2003). Development and empirical assessment of a three- dimensional wisdom scale. Research on Aging, 25, 275324.

Baer, R. A. (2003). Mindfulness training as a clinical intervention: A conceptual and empirical review. Clinical Psychology: Science and Practice, 10, 125-143.

Baer, R. A., Smith, G. T., Lykins, E., Button, D., Krietemeyer, J., Sauer, S., ... \& Williams, J. M. G. (2008). Construct validity of the five facet mindfulness questionnaire in meditating and nonmeditating samples. Assessment, 15, 329-342.

Bishop, S. R., Lau, M. A., Shapiro, S. L., Carlson, L., Anderson, N. D., Carmody, J.,...Devins, G. (2004). Mindfulness: A proposed operational definition. Clinical Psychology, 11, 230-241.

Batson, C. D. \& Schoenrade, P. A. (1991). Measuring religion as a quest: 2.) Reliability concerns. Journal of Scientific Study of Religion, 30, 430-447.

Brinthaupt, T. M., Hein, M. B., \& Kramer, T. E. (2009). The selftalk scale: Development, factor analysis, and validation. Journal of Personality Assessment, 91, 82-92.

Brown, K. W., Ryan, R. M., \& Creswell, J. D. (2007). Mindfulness: Theoretical foundations and evidence for its salutary effects. Psychological Inquiry, 18, 211-237.

Chiesa, A., Serretti, A., \& Jakobsen, J. C. (2013). Mindfulness: Top-down or bottom-up emotion regulation strategy? Clinical Psychology Review, 33, 82-96.

Creswell, J. D., \& Lindsay, E. K. (2014). How does mindfulness training affect health? A mindfulness stress buffering account. Current Directions in Psychological Science, 23, 401-407.

Davis, P. E., Meins, E., \& Fernyhough, C. (2013). Individual differences in children's private speech: The role of imaginary companions. Journal of Experimental Child Psychology, 116, 561571.

Donnellan, M. B., Oswald, F. L., Baird, B. M., \& Lucas, R. E. (2006). The mini-IPIP scales: Tiny-yet-effective measures of the Big Five factors of personality. Psychological Assessment, 18, 192-203.

Duncan, R. M., \& Cheyne, J. A. (1999). Incidence and functions of self-reported private speech in young adults: A self-verbalization questionnaire. Canadian Journal of Behavioural Science, 31, 133-136.

Emerson, M. J., \& Miyake, A. (2003). The role of inner speech in task switching: A dual-task investigation. Journal of Memory and Language, 48, 148-168.

Everett, J. A. (2013). The 12 item social and economic conservatism scale (SECS). PloS One, 8.

Fernyhough, C. (2008). Getting Vygotskian about theory of mind: Mediation, dialogue, and the development of social understanding. Developmental Review, 28, 225-262.
Flury, J. M., \& Ickes, W. (2007). Having a weak versus strong sense of self: The Sense of Self Scale (SOSS). Self and Identity, 6, 281-303.

Fresco, D. M., Moore, M. T., van Dulmen, M. H., Segal, Z. V., Ma, S. H., Teasdale, J. D., \& Williams, J. M. G. (2007). Initial psychometric properties of the experiences questionnaire: validation of a self-report measure of decentering. Behavior Therapy, 38, 234-246.

Gade, M., \& Paelecke, M. (2019). talking matters-evaluative and motivational inner speech use predicts performance in conflict tasks. Scientific reports, 9, 1-8.

Garvey, K. J., \& Ford, T. G. (2014). Rationality, political orientation, and the individualizing and binding moral foundations. Letters on Evolutionary Behavioral Science, 5, 9-12.

Grabovac, A. D., Lau, M. A., \& Willett, B. R. (2011). Mechanisms of mindfulness: A Buddhist psychological model. Mindfulness, 2, 154-166.

Graham, J., Haidt, J., Koleva, S., Motyl, M., Iyer, R., Wojcik, S. P., \& Ditto, P. H. (2013). Moral foundations theory: The pragmatic validity of moral pluralism. Advances in Experimental Social Psychology, 47, 55-13.

Gross, J.J., \& John, O.P. (2003). Individual differences in two emotion regulation processes: Implications for affect, relationships, and well-being. Journal of Personality and Social Psychology, 85, 348-362.

Haidt, J. (2012). The righteous mind: Why good people are divided by politics and religion. New York: Pantheon.

Heavey, C. L., \& Hurlburt, R. T. (2008). The phenomena of inner experience. Consciousness and Cognition, 17, 798-81.

Hölzel, B. K., Lazar, S. W., Gard, T., Schuman-Olivier, Z., Vago, D. R., \& Ott, U. (2011). How does mindfulness meditation work? Proposing mechanisms of action from a conceptual and neural perspective. Perspectives on Psychological Science, 6, 537-559.

Jones, P. E. (2009). From 'external speech' to 'inner speech' in Vygotsky: A critical appraisal and fresh perspectives. Language \& Communication, 29, 166-181.

Karbach, J., \& Kray, J. (2007). Developmental changes in switching between mental task sets: The influence of verbal labeling in childhood. Journal of Cognition and Development, 8, 205-236.

Kompa, N. A., \& Mueller, J. L. (2020). How abstract (non-embodied) linguistic representations augment cognitive control. Frontiers in Psychology, 11.

Levenson, R., Jennings, P.A., Aldwin, C., \& Shiraishi, R.W. (2005). Self-transcendence, conceptualization and measurement. International Journal of Aging \& Human Development, 60, $127-$ 143.

Lundman, B., Strandberg, G., Eisemann, M., Gustafson, Y., \& Brulin, C. (2007). Psychometric properties of the Swedish version of the Resilience Scale. Scandinavian Journal of Caring Sciences, 21, 229-237.

Mason, W., \& Suri, S. (2012). Conducting behavioral research on Amazon's Mechanical Turk. Behavior Research Methods, 44, 123.

McCarthy-Jones, S., \& Fernyhough, C. (2011). The varieties of inner speech: Links between quality of inner speech and psychopathological variables in a sample of young adults. Consciousness and Cognition, 20, 1586-1593.

Miyake, A., Emerson, M. J., Padilla, F., \& Ahn, J. C. (2004). Inner speech as a retrieval aid for task goals: The effects of cue type and articulatory suppression in the random task cuing paradigm. Acta Psychologica, 115, 123-142.

Mooijman, M., Meindl, P., Oyserman, D., Monterosso, J., Dehghani, M., Doris, J. M., \& Graham, J. (2018). Resisting temptation for the good of the group: Binding moral values and the moralization of self-control. Journal of Personality and Social Psychology, 115, 585-599.

Morin, A. (2018). The self-reflective functions of inner speech: Thirteen years later. In P. Langland-Hassan \& A. Vicente (Eds.), 
Inner speech: New voices (pp. 276-298). New York: Oxford University Press.

Morin, A., Everett, J., Turcotte, I., \& Tardif, G. (1993). Le dialogue interieur comme mediateur cognitif de la conscience de soi privee: Une mesure de l'activite de se parler soi-meme a propos de soi et une etude [Self-talk as a mediator of private self-consciousness: A measure of the activity to talk to oneself about oneself and a correlational study], La Revue Quebecoise de Psychologie, 14, 3-19.

Müller, U., Jacques, S., Brocki, K., \& Zelazo, P. D. (2009). The executive functions of language in preschool children. In A. Winsler, C. Fernyhough, \& I. Montero (Eds.), Private speech, executive functioning, and the development of verbal self-regulation (pp. 53-68). New York: Cambridge University Press.

Nolan, S. A., Roberts, J. E., \& Gotlib, I. H. (1998). Neuroticism and ruminative response style as predictors of change in depressive symptomatology. Cognitive Therapy and Research, 22, 445-455.

Nolen-Hoeksema, S. (1991). Responses to depression and their effects on the duration of depressive episodes. Journal of Abnormal Psychology, 100, 569-582.

Raes, F., Pommier, E., Neff, K. D., \& Van Gucht, D. (2011). Construction and factorial validation of a short form of the self-compassion scale. Clinical Psychology \& Psychotherapy, 18, 250255.

Ryff, C. D., \& Keyes, C. L. M. (1995). The structure of psychological well-being revisited. Journal of Personality and Social Psychology, 69, 719-727.

Sahdra, B. K., Shaver, P. R., \& Brown, K. W. (2010). A scale to measure nonattachment: A Buddhist complement to Western research on attachment and adaptive functioning. Journal of Personality Assessment, 92, 116-127.

Schneider, J. F. (2002). Relations among self-talk, self-consciousness, and self-knowledge. Psychological Reports, 91, 807-812.

Schneider, J. F., Pospeschill, M., \& Ranger, J. (2005). Self-consciousness as a mediator between self-talk and self- knowledge. Psychological Reports, 96, 387-396.

Segal, Z. V., Williams, J. M. G., \& Teasdale, J. D. (2013). Mindfulness-based cognitive therapy for depression (2nd ed.). New York: Guilford.
Shapiro, S. L., Carlson, L. E., Astin, J. A., \& Freedman, B. (2006). Mechanisms of mindfulness. Journal of Clinical Psychology, 62, 373-386.

Shiota, M. N., Keltner, D., \& John, O. P. (2006). Positive emotion dispositions differentially associated with Big Five personality and attachment style. The Journal of Positive Psychology, 1, 6171.

Siegrist, M. (1995). Inner speech as a cognitive process mediating self-consciousness and inhibiting self-deception. Psychological Reports, 76, 259-265.

Trani, A., Rubinsztain, V. \& Verhaeghen, P. (in preparation). The Broad Rumination Scale.

Trapnell, P. D., \& Campbell, J. D. (1999). Private self-consciousness and the five-factor model of personality: distinguishing rumination from reflection. Journal of Personality and Social Psychology, 76, 284-304.

Vago, D. R., \& Silbersweig, D. A. (2012). Self-awareness, selfregulation, and self-transcendence (S-ART): A framework for understanding the neurobiological mechanisms of mindfulness. Frontiers in Human Neuroscience, 6.

Verhaeghen, P. (2019a). The mindfulness manifold: Exploring how self-preoccupation, self-compassion, and self-transcendence translate mindfulness into positive psychological outcomes. Mindfulness, 10, 131-145.

Verhaeghen, P. (2019b). The examined life is wise living: The relationship between mindfulness, wisdom, and the moral foundations. Journal of Adult Development. Advance online publication.

Verhaeghen, P., \& Aikman, S. N. (2020). How the mindfulness manifold relates to the five moral foundations, prejudice, and awareness of privilege. Mindfulness, 11, 241-254.

Vygotsky, L. S. (1934/1978). Mind in society: Development of higher psychological processes. Cambridge, MA: Harvard University Press.

Webster, J. D. (2003). An exploratory analysis of a self-assessed wisdom scale. Journal of Adult Development, 10, 13-22.

Whitmer, A. J., \& Banich, M. T. (2007). Inhibition versus switching deficits in different forms of rumination. Psychological science, 18, 546-553. 


\section{Appendix}

Principal component analysis (oblimin rotation), extracting 8 factors from the Self-Verbalization Questionnaire and the Varieties of Inner Speech Questionnaire.

Item

number
Item

\begin{tabular}{|c|c|c|c|c|c|c|}
\hline 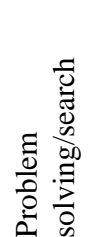 & 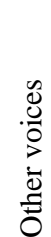 & 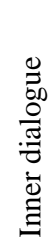 & 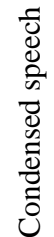 & 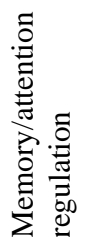 & 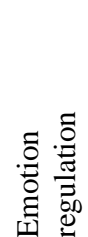 & 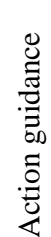 \\
\hline
\end{tabular}

SVQ23 I sometimes think out loud to myself when I'm trying to solve a puzzle

SVQ12 I sometimes think out loud to myself when I'm working on a crossword puzzle

SVQ18 I sometimes guide myself using speech when I'm searching through a newspaper or a magazine.

SVQ20 I sometimes think out loud to myself when I'm looking for a number in the phone book.

SVQ22 I sometimes think out loud to myself when I'm doing mental arithmetic.

SVQ17 I sometimes verbalize my thoughts when I'm searching for a book in a library.

VISQ4 I experience the voices of other people asking me questions in my head

VISQ5 I hear other people's voices nagging me in my head

VISQ3 I hear the voice of another person in my head. For example, when I have done something foolish I hear my mother's voice criticizing me in my mind

VISQ12 I hear other people's actual voices in my head, saying things that they have never said to me before

VISQ16 I hear other people's actual voices in my ahead, saying things that they actually once said to me

VISQ6 My thinking in words is more like a dialogue with myself, rather than my own thoughts in a monologue

VISQ10 When I am talking to myself about things in my mind, it is like I am having a conversation with myself

VISQ13 I talk back and forward to myself in my mind about things

VISQ2 When I am talking to myself about things in my mind, it is like I am going back and forward asking myself questions and then answering them

VISQ8 My thinking to myself in words is like shorthand notes, rather than full, proper, grammatical English

VISQ14 My thinking in words is shortened compared to my normal out loud speech. For example, rather than saying to myself things like 'I need to go to the shops', I will just say 'shops' to myself in my head

VISQ1 I think to myself in words using brief phrases and single words rather than full sentences

VISQ15 If I were to write down my thoughts on paper, they would read like a normal grammatical sentence

VISQ7 I think to myself in words using full sentences

SVQ5 I sometimes think out loud to myself when I 'm memorizing something for an exam.

SVQ6 I sometimes think out loud to myself when I need to remember a phone number.

SVQ1 I sometimes verbalize my thoughts when I'm working on a difficult problem.

SVQ2 I sometimes think out loud to myself when I'm trying to write with a lot of distraction.

SVQ7 I sometimes plan my actions out loud when I'm getting organized.

SVQ13 I sometimes think out loud to myself when I'm proof-reading something I've written.

SVQ24 I sometimes verbalize my thoughts when I'm feeling angry or upset about something.

SVQ27 I sometimes verbalize my thoughts when I'm feeling disappointed about something.

SVQ21 I sometimes verbalize my thoughts when I'm trying not to get angry. 
Appendix continued

SVQ15 I sometimes verbalize my thoughts when I discover that I've locked my keys inside my car or my home.

0.45

SVQ3 I sometimes verbalize my thoughts when I'm playing a computer game or video game.

SVQ14 I sometimes verbalize my thoughts when I'm learning to use new computer software.

SVQ19 I sometimes guide myself using speech when I'm driving an unfamiliar car.

SVQ11 I sometimes verbalize my thoughts when I'm deciding whether I've done a good job.

SVQ9 I sometimes guide my actions using speech when I use unfamiliar equipment

SVQ4 I sometimes think out loud to myself when I'm trying to organize pages of notes.

SVQ8 I sometimes think out loud to myself when I'm trying to clean up a mess in a big hurry. (8)

VISQ11 I talk silently to myself telling myself to do things.

VISQ9 I think in inner speech about what I have done, and whether it was right or not.

VISQ17 I talk silently to myself telling myself not to do things.

VISQ18 I evaluate my behavior using my inner speech. For example I say to myself, 'that was good' or 'that was stupid'. 